\title{
Site Amplifications for Generic Rock Sites
}

\author{
by David M. Boore and William B. Joyner
}

\begin{abstract}
Seismic shear-wave velocity as a function of depth for generic rock sites has been estimated from borehole data and studies of crustal velocities, and these velocities have been used to compute frequency-dependent amplifications for zero attenuation for use in simulations of strong ground motion. We define a generic rock site as one whose velocity at shallow depths equals the average of those from the rock sites sampled by the borehole data. Most of the boreholes are in populated areas; for that reason, the rock sites sampled are of particular engineering significance. We consider two generic rock sites: rock, corresponding to the bulk of the borehole data, and very hard rock, such as is found in glaciated regions in large areas of eastern North America or in portions of western North America. The amplifications on rock sites can be in excess of 3.5 at high frequencies, in contrast to the amplifications of less than 1.2 on very hard rock sites. The consideration of unattenuated amplification alone is computationally convenient, but what matters for ground-motion estimation is the combined effect of amplification and attenuation. For reasonable values of the attenuation parameter $\kappa_{0}$, the combined effect of attenuation and amplification for rock sites peaks between about 2 and $5 \mathrm{~Hz}$ with a maximum level of less than 1.8 . The combined effect is about a factor of 1.5 at $1 \mathrm{~Hz}$ and is less than unity for frequencies in the range of 10 to $20 \mathrm{~Hz}$ (depending on $\kappa_{0}$ ).

Using these amplifications, we find provisional values of about $\Delta \sigma=70$ bars and $\kappa_{0}=0.035 \mathrm{sec}$ for rock sites in western North America by fitting our empirically determined response spectra for an $\mathbf{M} 6.5$ event to simulated values.

The borehole data yield shear velocities $\left(\bar{V}_{30}\right)$ of 618 and $306 \mathrm{~m} / \mathrm{sec}$ for "rock" and "soil" sites, respectively, when averaged over the upper $30 \mathrm{~m}$. From this, we recommend that $\bar{V}_{30}$ equals 620 and $310 \mathrm{~m} / \mathrm{sec}$ for applications requiring the average velocity for rock and soil sites in western North America.

By combining the amplifications for rock sites and the site factors obtained from our analysis of strong-motion data, we derive amplifications for sites with $\vec{V}_{30}=$ $520 \mathrm{~m} / \mathrm{sec}$ (NEHRP class C, corresponding to a mix of rock and soil sites) and $\bar{V}_{30}$ $=310$ and $255 \mathrm{~m} / \mathrm{sec}$ (average soil and NEHRP class D sites, respectively). For the average soil site, the combined effect of amplification and attenuation exceeds a factor of 2.0 for frequencies between 0.4 and about $4 \mathrm{~Hz}$, with a peak site effect of 2.4; the peak of the NEHRP class D site effect is 2.7 .
\end{abstract}

\section{Introduction}

Simulations of ground motions are often needed on rock sites, e.g., for use in seismic design and building codes. As is the case for soil sites, not all rock sites are created equal, and for site-specific applications, the properties of the local site should be used in the simulations. In many cases, however, it is sufficient to do the simulations for a representative or generic rock site. The main purpose of this article is to present average velocity versus depth and amplification versus frequency for such sites. The amplifications can be used directly in the stochastic model for simulating earthquake ground motions (e.g., Boore, 1996). This article is an extension and improvement of the rock amplifications in Boore
(1986). Silva and Darragh (1995) and Steidl et al. (1996) have also considered site amplifications for rock sites.

The amplifications are based on shear velocity and density as functions of depth. We use an extensive set of shearwave travel-time measurements made in boreholes to constrain the shallow velocities, and we use studies of $P$-wave velocities in the crust as a guide for choosing the deeper velocities. The amplifications are computed using the quarter-wavelength approximation introduced by Joyner $e t a l$. (1981). The approximation is checked using wave propagation to calculate the exact response of the velocity structure used in the quarter-wavelength approximation. 
The structure of the article is as follows: We first discuss the quarter-wavelength approximation, and then we use this approximation to obtain the amplification function for each borehole, as well as the average over all the boreholes. In order to obtain amplifications over a wider range of frequencies, velocity and density at greater depths than those for most of the boreholes are needed, and we next discuss our model for the deeper velocities and densities. The computed amplifications are then presented, followed by checks of these amplifications using wave propagation. We use the amplifications in a determination of the parameters $\kappa_{0}$ and $\Delta \sigma$ required to fit our empirically determined response spectra for earthquakes in western North America at a particular magnitude and distance. (Along with seismic moment, $\Delta \sigma$ controls the high-frequency spectral amplitude; $\kappa_{0}$ is the zero-distance intercept of the high-frequency decay parameter $\kappa$ introduced by Anderson and Hough, 1984). We then present a discussion of the average shear-wave velocities, $\bar{V}_{30}$, for "rock" and "soil" sites, found from an analysis of the borehole database. We conclude by deriving amplification factors for sites with $\bar{V}_{30}=520,310$, and $255 \mathrm{~m} / \mathrm{sec}$. These values were chosen as characteristic of National Earthquake Hazard Reduction Program (NEHRP) class C, soil, and NEHRP class D sites, respectively [see BSSC (1994) for a description of the NEHRP site categories].

Most of the article is devoted to the estimation of amplification at sites on rock, such as commonly found in western North America (most of the data used in this article have been obtained from sites in coastal California). We also give results for a very hard rock site. Sites underlain by very hard rock are common in glaciated parts of eastern North America, but they also exist in portions of western North America; for this reason, we have decided not to apply regional labels to our amplification functions, even though more engineered structures are founded on very hard rock sites in eastern North America than in western North America. Even though the data we use come from restricted geographic regions, we hope that the results have more general applicability.

\section{The Quarter-Wavelength Approximation}

The quarter-wavelength approximation for computing site amplification was introduced by Joyner et al. (1981). For a particular frequency, the amplification is given by the square root of the ratio between the seismic impedance (velocity times density) averaged over a depth corresponding to a quarter wavelength and the seismic impedance at the depth of the source (as used here, the averages of the seismic velocity and density are determined separately instead of their product being averaged; this should make little difference in the results). Day (1996) has provided some theoretical justification for the method. The approximation is relatively insensitive to discontinuities in seismic velocity; the method does not produce the peaks and valleys that are due to the interference of multiply reflected waves. We consider this lack of resonant effects to be an advantage if a smoothed amplification function is desired, as it is in this article.

Comparisons of the approximate and exact theoretical amplifications include those of Boore and Joyner (1991), Boatwright (personal comm., 1987), and Silva and Darragh (1995); we include another comparison in this article. The available comparisons suggest that the quarter-wavelength approximation provides a good estimate of the mean values of the response.

The algorithm is the following: the $S$ travel time $S_{t t}(z)$ from the surface to depth $z$ either is taken from downhole surveys or is computed using shear velocity as a function of depth; the average velocity to depth $z, \bar{\beta}(z)$, is $z / S_{t t}(z)$, and the frequency corresponding to the depth, $f(z)$, is $1 /[4 \times$ $S_{t r}(z)$ ]; a travel-time-weighted average is taken of the density, $\bar{\rho}(z)$; and the amplification $A(f)$ is given by

$$
A[f(z)]=\sqrt{\rho_{s} \beta_{s} / \bar{\rho}(z) \bar{\beta}(z)},
$$

where the subscript $s$ represents values in the vicinity of the source.

When we refer to amplification, we mean the Fourier amplitude spectrum of the surface motion produced for $u n$ attenuated incident plane waves divided by the Fourier amplitude spectrum that would have been recorded at the surface of a uniform half-space by the same incident plane waves (the amplification therefore approaches unity for very long-period waves). Of course, the site response of interest includes attenuation, but we have considered the amplification and attenuation separately because we prefer to parameterize the attenuation by the operator $\exp \left(-\pi \kappa_{0} f\right)$. By so doing, it is natural in computer simulations to treat the amplification and attenuation as separate entities, though this distinction may be somewhat artificial. A careful study of the response of a particular site to seismic waves should include attenuation as a point property with depth. Even then it is important to recognize that using a parameter such as $Q$ to represent the attenuation is only a phenomenological description of a complex process involving intrinsic and scattering attenuation mechanisms.

\section{Amplification from Borehole Data}

The travel time of $S$ waves from the surface to any depth below a site is the fundamental property needed for the determination of the amplification (velocities, of course, can be determined from $S_{t t}$ ). These travel times are available from downhole surveys made in boreholes and can be used to estimate directly the amplification at high frequencies. We have entered all the $S_{t t}$ from over 210 boreholes logged over the past 20 years by J. Gibbs, T. Fumal, and colleagues (Fumal et al., 1981, 1982a, 1982b, 1984; Gibbs, 1989; Gibbs et al., 1975, 1976, 1977, 1980, 1990, 1992, 1993, 1994a, 1994b; Gibbs and Fumal, 1994); in addition, we have added data from a few other published studies (Fletcher et al., 1990; Thiel and Schneider, 1993) and from several unpub- 
lished studies (written communications from J. Gibbs, 1995 and T. Fumal, 1996). We then assigned a rock or soil classification to each borehole, based on surficial geology, following Joyner and Boore's (1981) scheme that rock sites are those described by terms such as "granite," "diorite," "gneiss," "chert," "graywacke," "limestone," "sandstone," or "siltstone," as long as the rock is overlain by less than 4 to $5 \mathrm{~m}$ of soils. The distribution of shear velocity averaged over the upper $30 \mathrm{~m}$ (most of the holes were $30 \mathrm{~m}$ or shallower) is shown in Figure 1 for the two subsets of the borehole database. In the subsequent analysis, we use only the data from 57 rock boreholes.

The tabulated travel times for each hole were converted into $f(z)$ and $A[f(z)]$. The results are plotted in Figure 2. The apparent trends with slope $d \log A / d \log f=-0.5$ correspond to measurements at the same depths. Also shown in the figure is the amplification obtained by averaging the amplifications and frequencies at each depth. The apparent multiple-valued amplification at low frequencies is an artifact of the fact that the averages are along lines of constant depth. Furthermore, the errors in amplification and frequency are correlated, and the error bars should be oriented along the constant-depth trends; for simplicity, they have been determined independently - the errors as shown, however, are an adequate indicator of the errors in the determinations. As expected, the amplification increases with frequency, reaching values larger than a factor of 3.5 for average rock sites. The scatter in amplification at any frequency is large, not surprisingly being on the order of the scatter about regression fits to strong-motion data (presumably much of that scatter is due to variations in site response for a given class of sites).

\section{Velocity and Density Structure}

\section{Rock Site}

Although Figure 2 gives an initial idea of the amplifications and a sense for the scatter in the amplifications from individual rock sites, it does not provide good estimates for frequencies less than about $3 \mathrm{~Hz}$, for which we are running out of borehole data at the necessary depths. For this reason, we need to estimate $S_{t t}$ at greater depths. Direct measurements are rare, so we have resorted to estimating the velocity as a function of depth and then computing $S_{t t}$ from this velocity. Our velocity function is constructed by using the borehole results to determine the best average shallow velocity, and then using $P$-wave velocities in the crust based on velocity surveys and earthquake location studies to estimate deeper $S$-wave velocities on the assumption that Poisson's ratio is close to 0.25 at depths in excess of several kilometers. We patch together the shallow and deeper velocity functions in order to obtain a continuous velocitydepth function.

The shallow velocity is obtained by interpolating the observed times at 2-m intervals from the surface to the deep-
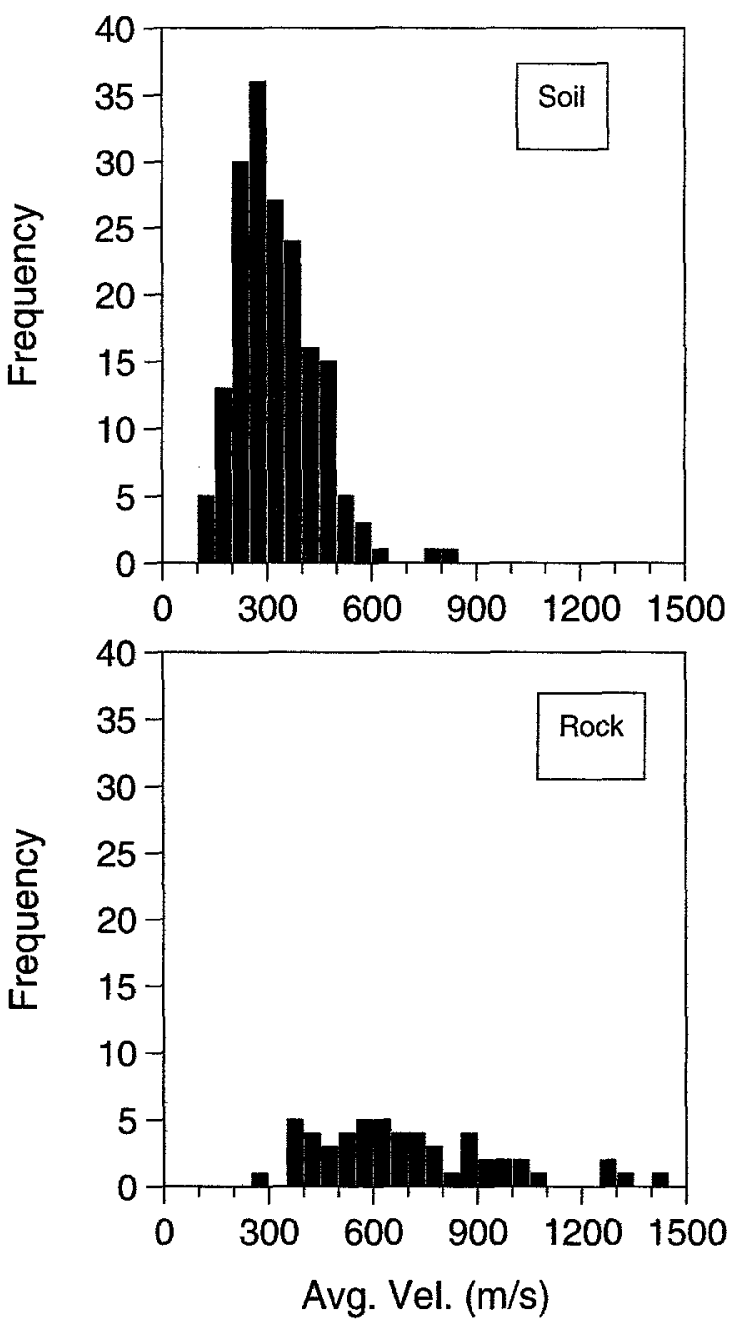

Figure 1. Histograms of shear velocity averaged over the upper $30 \mathrm{~m}$, from downhole surveys in boreholes. Many of the boreholes did not quite reach 30 $\mathrm{m}$, and for the sake of estimating representative velocity distributions, small extrapolations of the travel time to $30 \mathrm{~m}$ were used in computing the average velocities. The subsequent analysis of the shallow velocities in this article make no use of such extrapolations. Fitting travel-time curves to the observed travel times gives average velocities of 618 and 306 $\mathrm{m} / \mathrm{sec}$ for rock and soil boreholes, respectively.

est recording in each hole, averaging $S_{t t}$ at each depth for which at least two interpolated values are available, fitting a functional form to the average $S_{t t}$ as a function of depth, and converting this average travel time into a velocity-depth function. Figure 3 shows the individual travel times, the geometrically averaged travel times, a power law fit to the averages (determined using unweighted least-squares) between 0 and $30 \mathrm{~m}$, and the number of data points for each depth. Straightforward differentiation of the travel-time function yields the following equation for the shear velocity:

$$
\beta(z)=2.206 z^{0.272},
$$




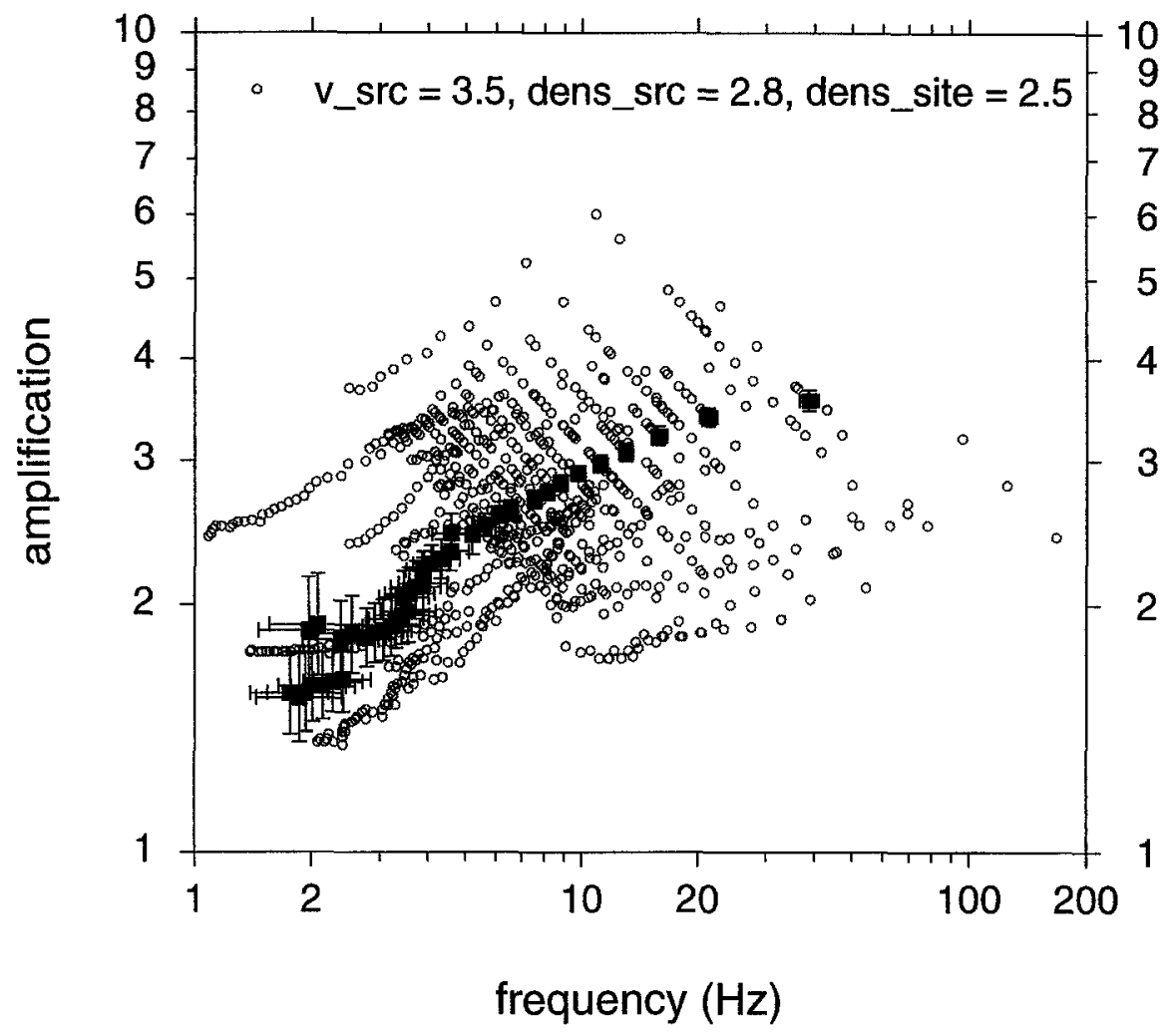

Figure 2. Amplifications based on $S$ travel times and the quarter-wavelength approximation from individual rock boreholes (circles) and geometric averages over all boreholes (filled squares). The source velocity and density assumed in the amplification calculation was $3.5 \mathrm{~km} / \mathrm{sec}$ and $2.8 \mathrm{gm} / \mathrm{cc}$, and the density at the surface was $2.5 \mathrm{gm} /$ $\mathrm{cc}$. The trends with negative slope are values from various boreholes at the same depth. The error bars are plus and minus one standard error of the mean values (standard deviation divided by the square root of the number of observations). To improve clarity, many of the averaged points have been removed from the plot at low frequencies; the trends shown are the same as would be seen using the complete set of averages.

with the units of $\beta$ and $z$ being $\mathrm{km} / \mathrm{sec}$ and $\mathrm{km}$, respectively. The power-law functional form was chosen after trials with several other forms. It has the advantage of providing a simple relation between travel time and velocity and a good fit to the observations, but it has the obvious disadvantage of predicting zero velocity at the surface. The value at $1-\mathrm{m}$ depth $(337 \mathrm{~m} / \mathrm{sec})$ is reasonable. We replace the velocity between 0 and $1-\mathrm{m}$ depth with a constant-velocity layer such that the travel time to $1 \mathrm{~m}$ equals that given by the powerlaw fit. The influence of these shallow depths on the amplification is only at very high frequencies (in excess of $30 \mathrm{~Hz}$ ), however, and, as shown later, attenuation will severely blunt the amplification at these frequencies. We use equation (2) for the shear-wave velocity between 0.001 and $0.03 \mathrm{~km}$.

Because of a lack of data, it is difficult to constrain the shear-wave velocity at greater depths. At depths below $4 \mathrm{~km}$, we estimate shear-wave velocity from compressional velocities, assuming a constant Poisson's ratio of 0.25 . We chose $4 \mathrm{~km}$ because the lithostatic pressure at this depth is about $1 \mathrm{kbar}$, the pressure at which most cracks should be closed and below which Poisson's ratio should be near 0.25 for the crustal rocks of concern to us (e.g., Clark, 1966; Christensen and Mooney, 1995; Christensen, 1996). There is good evidence that Poisson's ratio is not constant at shallower depths (e.g., Nicholson and Simpson, 1985), and for this reason, we cannot directly use the numerous measurements of crustal $P$-wave velocities obtained from refraction experiments and from earthquake location investigations to obtain $S$-wave velocities for depths less than $4 \mathrm{~km}$. Representative $P$-wave velocity profiles are shown in Figure 4 . We adjusted the parameters of a power-law functional form to agree roughly with the measured $P$-wave results below $4 \mathrm{~km}$ and converted this to a function giving $S$-wave velocity by dividing the $P$ wave velocities by $\sqrt{3}$. Our function is indicated by the heavy line in Figure 4.

We patch together the velocities at depths less than 0.03 $\mathrm{km}$ (from boreholes) and greater than $4 \mathrm{~km}$ (from $P$ waves) with two power-law functions. In doing this, we were guided by the $P$-wave velocities near $3.7 \mathrm{~km} / \mathrm{sec}$ at $0.2-\mathrm{km}$ depth for Franciscan rocks on either side of the southern San Francisco Bay (Hazlewood and Joyner, 1973; Hazlewood, 1974). For Poisson's ratio of 0.25 , this $P$-wave velocity yields an 


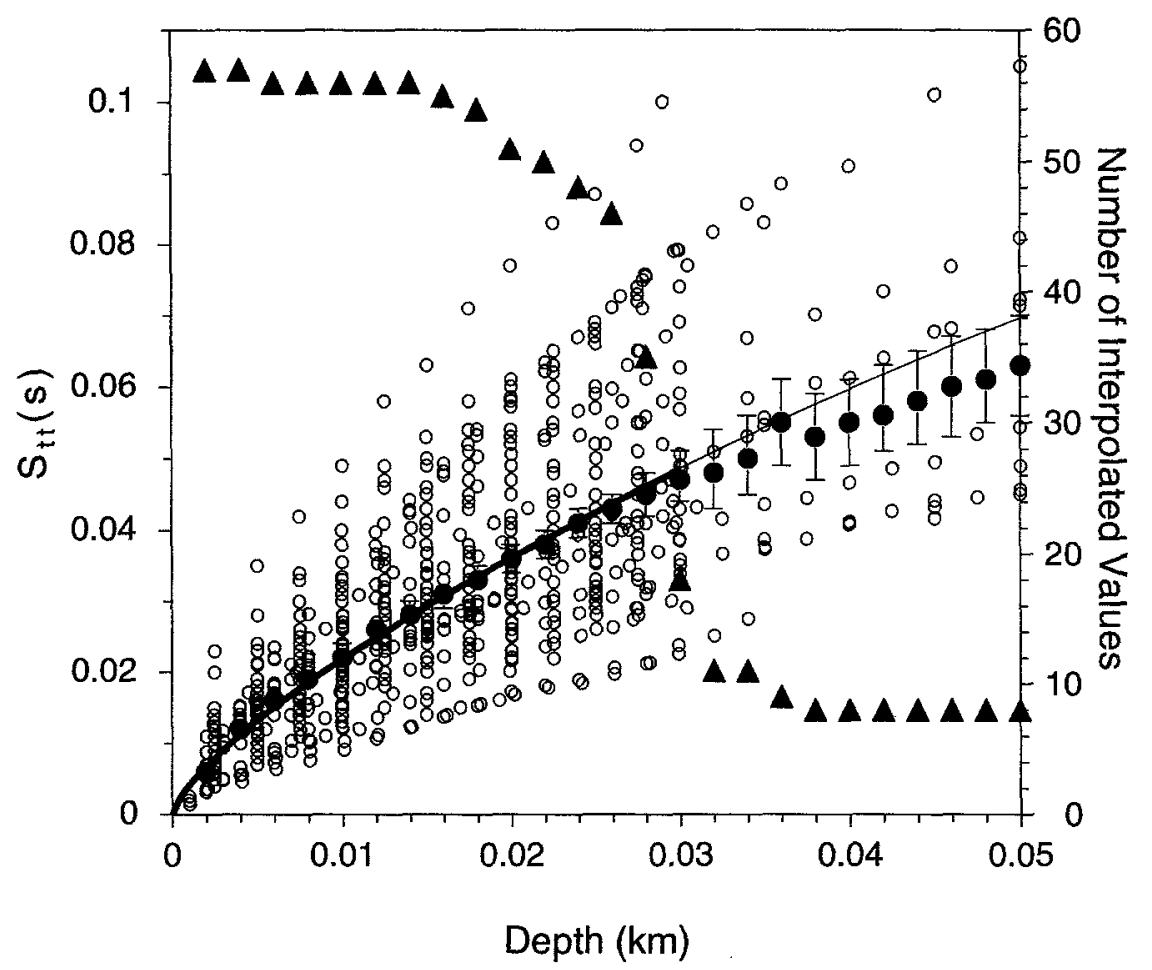

Figure 3. $S$-wave travel time versus depth (left axis). The circles are the individual observations, and the solid dots are the geometric means of the interpolated travel times, with standard error of the mean indicated by the error bars. The least-squares fit of a power law is given by the heavy line $\left(S_{t t}=0.623 z^{0.728}\right)$, and the travel time corresponding to the adopted velocity model is given by the light line (the travel time corresponding to the velocities in Table 1). The number of interpolated values at each depth is given by the filled triangles (right axis).

$S$-wave velocity of $2.1 \mathrm{~km} / \mathrm{sec}$; we consider this an upper bound and therefore constrained the velocity function to pass through a smaller value at a depth of $0.2 \mathrm{~km}$. Our final velocity model is tabulated in Table 1 and plotted in Figure 5.

Data are available from a few deep boreholes. The travel times from these boreholes were sampled too sparsely at shallow depths to allow them to be combined with the borehole data previously discussed, and so they did not enter into the average travel times shown in Figure 3. In Figure 6, we compare the travel times from these holes with those from our adopted model. The adopted model yields travel times lower than those in the Varian hole. This is what we desire, for the Varian hole is in Tertiary sedimentary rocks, and the rock site class we have in mind would also contain older rocks, with presumably faster velocities, and the mean velocity would exceed that for the Tertiary rocks. On the other hand, the model travel times are also lower than the Cajon Pass hole, which is in Mesozoic granitic rocks. Note, however, that the interval velocity from the Cajon Pass hole at depths between 1.5 and $3 \mathrm{~km}$ is higher than the velocity from the adopted model; the apparent slow times for the Cajon Pass hole are entirely due to the unusually slow travel time in the upper few hundred meters of the hole.

The density is given as a function of shear velocity by the simple relation

$$
\rho(z)=2.5+[\beta(z)-0.3] \times \frac{2.8-2.5}{3.5-0.3}
$$

with $\rho$ in $\mathrm{gm} / \mathrm{cc}$ and $\beta$ in $\mathrm{km} / \mathrm{sec}$. Equation (3) is a simple interpolation of end point values chosen by referring to various reference books and from personal experience of one of the authors (WBJ) in measuring densities; it is only to be used for shear velocities between 0.3 and $3.5 \mathrm{~km} / \mathrm{sec}$. A density of $2.5 \mathrm{gm} / \mathrm{cc}$ was assigned to velocities less than $0.3 \mathrm{~km} /$ sec. We note that the density near the surface is higher than often given in seismological models [e.g., Wald et al. (1991), assign a density of $1.5 \mathrm{gm} / \mathrm{cc}$ to the $0.1-\mathrm{km}$-thick surface layer, with a shear velocity of $1.0 \mathrm{~km} / \mathrm{sec}$. Holocene sand deposits with shear-wave velocities as low as $0.3 \mathrm{~km} / \mathrm{sec}$ have densities of $2.0 \mathrm{gm} / \mathrm{cc}$ or greater (e.g., Fumal, 1978, Fig. 16); we assume that rocks of comparable velocities would have densities at least this high.

\section{Very Hard Rock Site}

For eastern North America, a number of structures are founded on very hard rock sites, such as those that have been stripped of the overlying weathered layer by glacial erosion (similar sites of engineering interest might be found in northwestern Washington and southwestern British Columbia). 


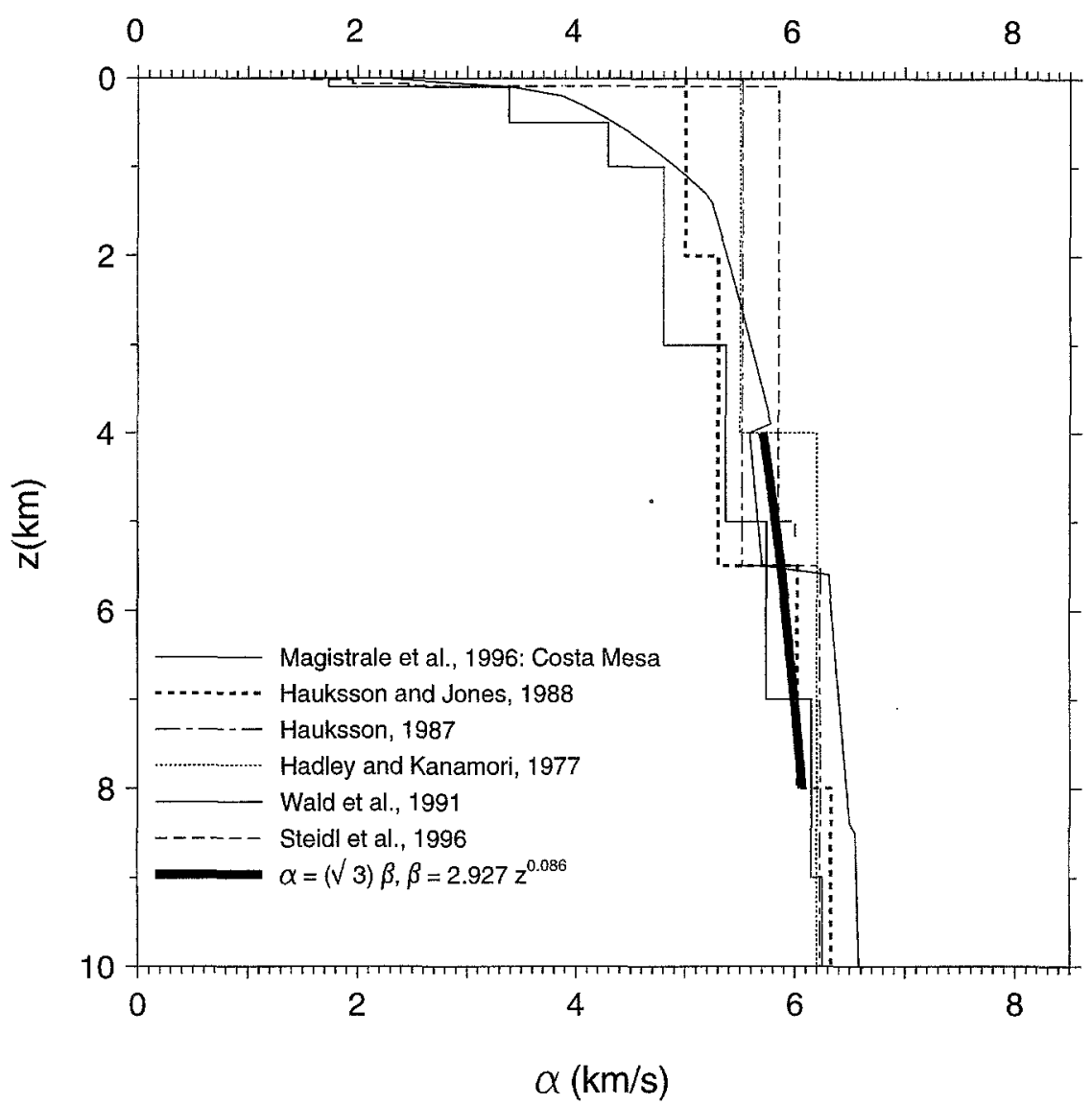

Figure 4. $P$ velocity versus depth to $10 \mathrm{~km}$. The heavy line is obtained by multiplying the generic rock shear velocities used in this article by $\sqrt{3}$; this assumes a Poisson's ratio of 0.25 , which we realize is much too small for shallow depths. The intent of this figure is to compare the final velocity profile used in the amplification calculation (heavy line) with various $P$ velocity profiles at depths greater than several kilometers, where we expect Poisson's ratio to be close to 0.25. The Magistrale $e t$ al. (1996) curve is for a point at $33.64^{\circ} \mathrm{N}$ and $117.93^{\circ} \mathrm{W}$.

Table 1

Velocity for Generic Rock Site

\begin{tabular}{cl}
\hline Depth $(\mathrm{km})$ & Shear Velocity $(\mathrm{km} / \mathrm{sec})^{*}$ \\
\hline$z \leqq 0.001$ & 0.245 \\
$0.001<z \leqq 0.03$ & $2.206 z^{0.272}$ \\
$0.03<z \leqq 0.19$ & $3.542 z^{0.407}$ \\
$0.19<z \leqq 4.00$ & $2.505 z^{0.199}$ \\
$4.00<z \leqq 8.00$ & $2.927 z^{0.086}$ \\
\hline
\end{tabular}

$* \bar{V}_{30}=0.618 \mathrm{~km} / \mathrm{sec}$

Silva and Darragh (1995) used a hole at Moodus, Connecticut, as the basis for the velocity in the upper $2.2 \mathrm{~km}$, and we use their velocities in our model for very hard rock sites. We estimate that the shear velocity at source depths is $3.6 \mathrm{~km} /$ sec, somewhat higher than that in western North America. [The velocity of $3.6 \mathrm{~km} / \mathrm{sec}$ is consistent with the summary of $P$-wave velocities for ENA shown in Fig. 5-15 of EPRI (1993) assuming that Poisson's ratio equals 0.25]. Fitting a power law to the velocities at 2.2 and $8.0 \mathrm{~km}$ produced a large kink in the velocity-depth function at $2.2 \mathrm{~km}$, so we have inserted an additional power-law fit between 0.75 and $2.2 \mathrm{~km}$. The velocity functions are given in Table 2 and are plotted in Figure 5. We obtain the densities from equation (3).

\section{Amplification from Velocity and Density Profiles}

We use the velocity and density functions to compute amplifications, using the quarter-wavelength approximation, and assuming that the velocity near the source is close to the velocity in our model at 8-km depth (the amplifications are only sensitive to variations of several kilometers in this source depth for frequencies less than $0.1 \mathrm{~Hz}$ ). The computations were made by program Site_Amp (Boore, 1996). The results are shown in Figure 7. The amplification for rock sites increases from near 1 at $0.1 \mathrm{~Hz}$ to over 3 for frequencies greater than about $12 \mathrm{~Hz}$. In contrast, the very hard rock amplification has a maximum of only 1.15 [it was for this reason that Boore and Atkinson (1987) and Atkinson and Boore (1995) ignored amplification in their simulations of 

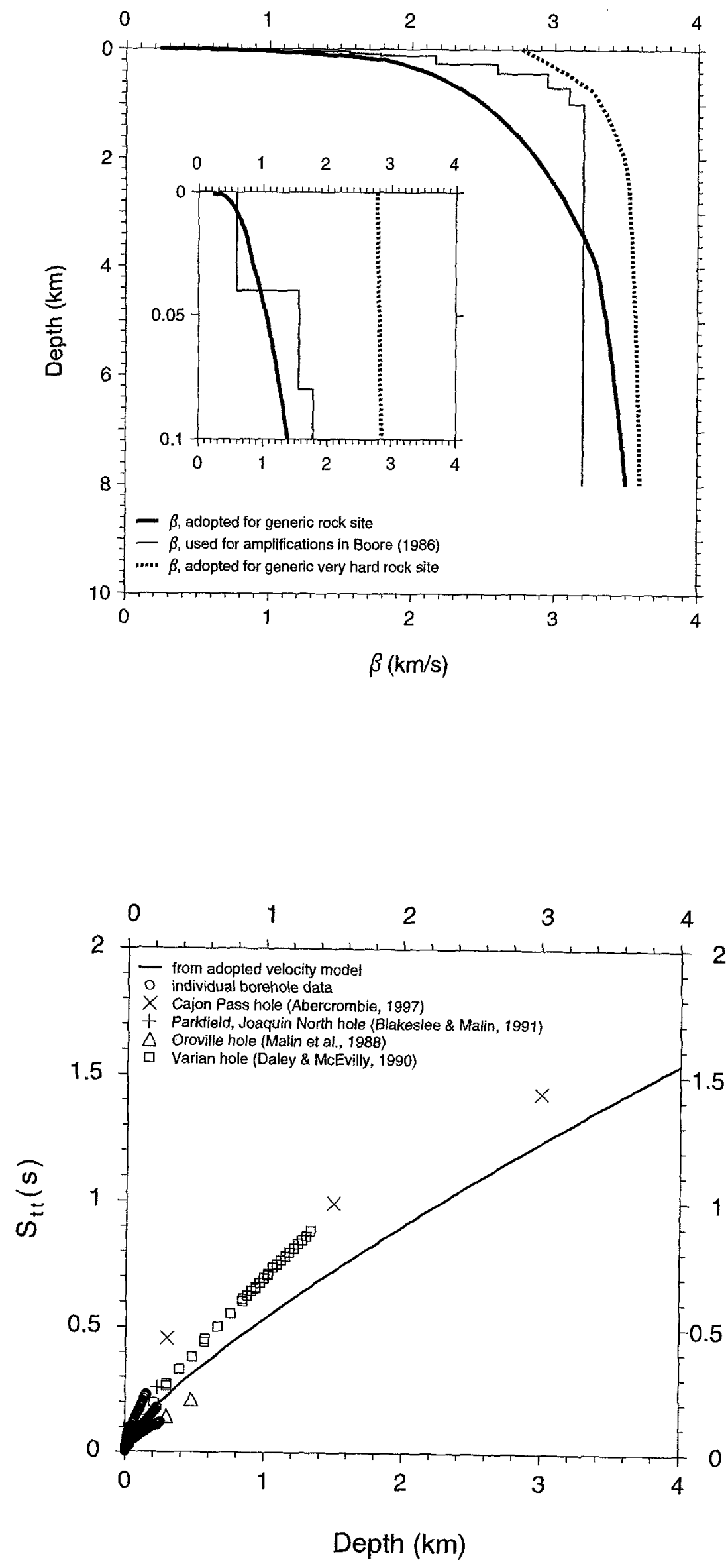

Figure 5. $S$ velocity versus depth adopted in this article for generic rock sites (heavy solid line) and generic very hard rock sites (heavy broken line). For comparison, the light line is the velocity model used to obtain the amplifications published in Boore (1986).

Figure 6. $S$ travel times from boreholes (references are given in the figure) and from the adopted model. The data from the Cajon Pass, Joaquin North, Oroville, and Varian holes were too sparsely sampled, especially at shallow depths, to be included in the travel-time averages shown in Figure 3. The data from the deeper boreholes provide guidance for the subjective estimation of the travel-time function at depths below about $30 \mathrm{~m}$. The Joaquin North and Varian holes are in Tertiary sediments, while the Cajon Pass and Oroville holes are largely in older crystalline rocks. Note that the Cajon Pass travel times are high because of the very slow travel time in the upper $300 \mathrm{~m}$; the velocities at depths of 1 to $3 \mathrm{~km}$ are higher than those in our adopted model, as we would expect. 
Table 2

Velocity for Generic Very Hard Rock Site

\begin{tabular}{cc}
\hline Depth $(\mathrm{km})$ & Shear Velocity $(\mathrm{km} / \mathrm{sec})^{*}$ \\
\hline 0.00 & 2.768 \\
0.05 & 2.808 \\
0.10 & 2.847 \\
0.15 & 2.885 \\
0.20 & 2.922 \\
0.25 & 2.958 \\
0.30 & 2.993 \\
0.35 & 3.026 \\
0.40 & 3.059 \\
0.45 & 3.091 \\
0.50 & 3.122 \\
0.55 & 3.151 \\
0.60 & 3.180 \\
0.65 & 3.208 \\
0.70 & 3.234 \\
0.75 & 3.260 \\
$0.75<z \leqq 2.20$ & $3.324 z^{0.067}$ \\
$2.20<z \leqq 8.00$ & $3.447 z^{0.0209}$ \\
\hline
\end{tabular}

$* \bar{V}_{30}=2.88 \mathrm{~km} / \mathrm{sec}$.

strong ground motion in eastern North America]. Also shown in Figure 7 is the amplification function used previously (Boore, 1986). In general, the new amplifications are greater than those used earlier.

In order to check the quarter-wavelength assumption, the velocity model was replaced with one consisting of a stack of constant-velocity layers (such that the travel time to each interface in the stack was the same as in the continuous velocity model), and the amplification was computed using the propagator-matrix method of Haskell (1960), as implemented by C. Mueller's program Rattle for $S H$ waves. (A $Q$ of 10,000 in each layer was used to simulate no attenuation.) Because the base of the velocity model is at $8 \mathrm{~km}$ in highvelocity material, incidence angles of $30^{\circ}$ and $45^{\circ}$ were used to approximate the range of angles that would exist for events not directly under the site (the incidence angles would be smaller for input at shallower depths because of refraction). The amplifications are shown in Figure 7. The oscillations at high frequencies are due to the finite thickness of the layering ( $1 \mathrm{~m}$ for the first two layers and $2 \mathrm{~m}$ to depths of $0.2 \mathrm{~km}$ ). The quarter-wavelength approximation is a good representation of the overall amplification; it has the advantages of being insensitive to the layering in the system, taking little computation time, and allowing back-of-the-envelope estimates of the amplification and the depths affecting various frequencies of motion.

For use in numerical simulations, it is convenient to approximate the amplification by a series of straight lines in log-amplification, log-frequency space (see Boore, 1996). This is conveniently done by specifying pairs of amplification, frequency points at the end points of the straight lines. Tables 3 and 4 contain a set of such pairs of points that give a good approximation to the quarter-wavelength amplifica- tions given in Figure 7 (as shown by the plus symbols in Fig. 7).

As discussed earlier, we choose to separate amplification and near-site attenuation for ease in incorporating the two effects in our computer codes for calculating ground motions; what counts for ground motions, of course, is the combined effect of amplification and attenuation. Figure 8 shows this combined effect for a range of values of the attenuation parameter $\kappa_{0}$ found by Silva and Darragh (1995) for rock sites in western North America [the amplification factors of Boore (1986) were used to obtain these estimates]. For reasonable values of $\kappa_{0}$ [i.e., in excess of 0.01 for most rock sites in western North America, although an average value of 0.005 was obtained by Hough et al. (1988) on granitic rocks in the Anza region of southern California], the large amplifications at high frequencies are greatly damped by the attenuation. It is important to note, however, that the overall effect of the amplification and attenuation is still larger than unity over a wide range of frequencies of engineering interest.

The quarter-wavelength approximation makes it easy to answer the question of what depth influences what frequency. The relationship between depth and frequency is shown in Figure 9 for our rock model. This figure shows that frequencies as low as $1 \mathrm{~Hz}$ are influenced by velocities in the upper few hundred meters of the Earth at rock sites. At soil sites, the primary influence on $1-\mathrm{Hz}$ amplification would be at even shallower depths. The velocity models used in the calculation of wave propagation in layered media should have near-surface velocities that are commensurate with the frequencies of the calculated motions. We fear that a number of seismologists use models with near-surface shear-wave velocities that are too high, thinking that the near-surface layers can be neglected without realizing that although the thickness is small, the travel time through the layers is not small.

\section{An Application: Preliminary Determination of $\Delta \sigma$ and $\kappa_{0}$}

Boore et al. (1992) used the amplification of Boore (1986) to determine the parameters $\Delta \sigma$ and $\kappa_{0}$ by fitting observed response spectra with simulations based on the stochastic model. The observed response spectra were obtained from the regression results of Joyner and Boore (1982). These regressions have been replaced with the interim results of Boore et al. (1993, 1994, 1997), while the current article replaces the Boore (1986) amplifications. It is thus timely to re-examine the conclusions reached by Boore $e t$ al. (1992). We show in Figure 10 the interim response spectra, computed for an unspecified mechanism, a horizontal distance of $20.0 \mathrm{~km}$ (the simulations used a slant distance of $20.7 \mathrm{~km}$ to account for the parameter " $\mathrm{h}$ " in the empirical regression equations), magnitude of 6.5 , average velocity to $30 \mathrm{~m}$ of $618 \mathrm{~m} / \mathrm{sec}$, and an averaged radiation pattern of 0.55 , overlain with simulated spectra using the amplification in 


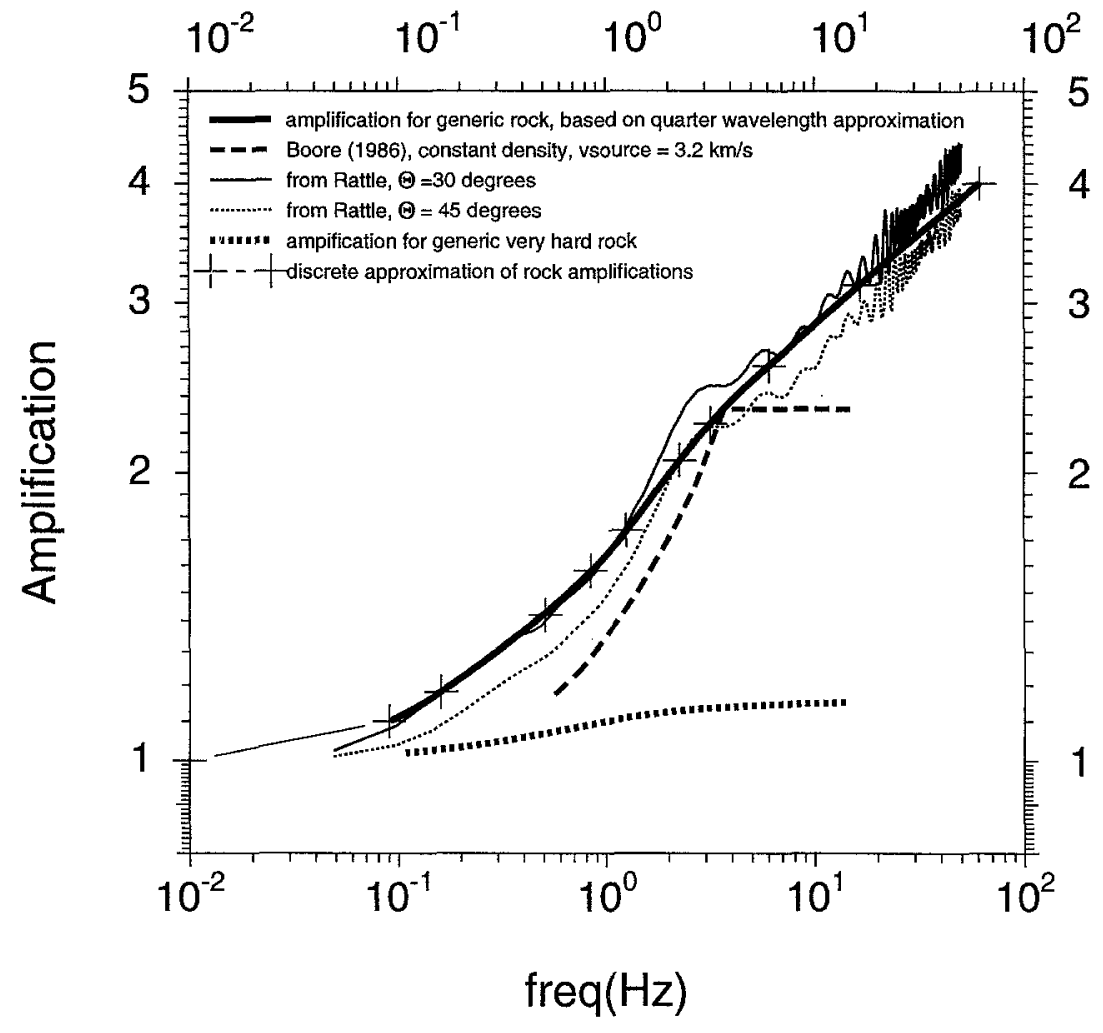

Figure 7. Amplification versus frequency. The heavy solid line is computed using the quarter-wavelength approximation and the velocity profile shown by the heavy solid line in Figure 5. The long-dashed line is from Boore (1986), also based on the quarter-wavelength approximation but using the "Boore (1986)" velocities shown in Figure 5. The results from plane $S H$ waves incident at the base of a $8-\mathrm{km}$ thick stack of constant-velocity layers (with $Q$ $=10,000$ ) closely approximating the adopted continuous shear-wave velocity are shown by the light lines for angles of incidence of $30^{\circ}$ and $45^{\circ}$; the results were computed from the Haskell matrix method, as implemented by program Rattle by C. Mueller. The quarterwavelength amplification for generic very hard rock is given by the heavy short-dashed line.
Table 3

Node Points of Amplification for Generic Rock Site $\left(\bar{V}_{30}=620 \mathrm{~m} / \mathrm{sec}\right)$

\begin{tabular}{cc}
\hline Frequency $(\mathrm{Hz})$ & Amplification* \\
\hline 0.01 & 1.00 \\
0.09 & 1.10 \\
0.16 & 1.18 \\
0.51 & 1.42 \\
0.84 & 1.58 \\
1.25 & 1.74 \\
2.26 & 2.06 \\
3.17 & 2.25 \\
6.05 & 2.58 \\
16.6 & 3.13 \\
61.2 & 4.00 \\
\hline
\end{tabular}

*Amplifications at other frequencies are obtained by interpolation, assuming a linear dependence between log frequency and log amplification (e.g., function site_amp_factor in rvtdsubs.for of Boore, 1996).

Table 3 and a suite of the parameters $\Delta \sigma$ and $\kappa_{0}$. Although the fit of the observed to the simulated spectra leaves much to be desired, we suggest that the best parameters to fit our spectra are $\Delta \sigma=70$ bars and $\kappa_{0}=0.035 \mathrm{sec}$. These values are close to those found by Youngs and Silva (1992). We also show a comparison with recent empirical results of Idriss (1993), Abrahamson and Silva (1995), and Sadigh et al. (1997) for rock sites and oblique faulting (estimated for the Sadigh et al. results by the geometric average of their strikeslip and reverse-slip motions). The best overall fit to these results is with $\Delta \sigma$ and $\kappa_{0}$ close to 100 bars and $0.040 \mathrm{sec}$,
Table 4

Node Points of Amplification for Generic Very Hard Rock Site $\left(\bar{V}_{30}=2900 \mathrm{~m} / \mathrm{sec}\right)$

\begin{tabular}{cc}
\hline Frequency $(\mathrm{Hz})$ & Amplification* $^{*}$ \\
\hline 0.01 & 1.00 \\
0.10 & 1.02 \\
0.20 & 1.03 \\
0.30 & 1.05 \\
0.50 & 1.07 \\
0.90 & 1.09 \\
1.25 & 1.11 \\
1.80 & 1.12 \\
3.00 & 1.13 \\
5.30 & 1.14 \\
8.00 & 1.15 \\
14.00 & 1.15
\end{tabular}

*Amplifications at other frequencies are obtained by interpolation, assuming a linear dependence between $\log$ frequency and log amplification (e.g., function site amp_factor in rvtdsubs. for of Boore, 1996).

respectively. For the moment magnitude of 6.5 for which the comparison is made in Figure 10, these values are similar to those found by Silva and Darragh (1995) in fitting earlier results of Sadigh et al. and by Atkinson and Silva (1997) in fitting empirical Fourier amplitude spectra for earthquakes in California. These two references, moreover, find that $\Delta \sigma$ is a decreasing function of moment magnitude. The $\kappa_{0}$ value is close to the rock value of 0.04 found by Anderson and Hough (1984) for recordings of the 1971 San Fernando earthquake. 


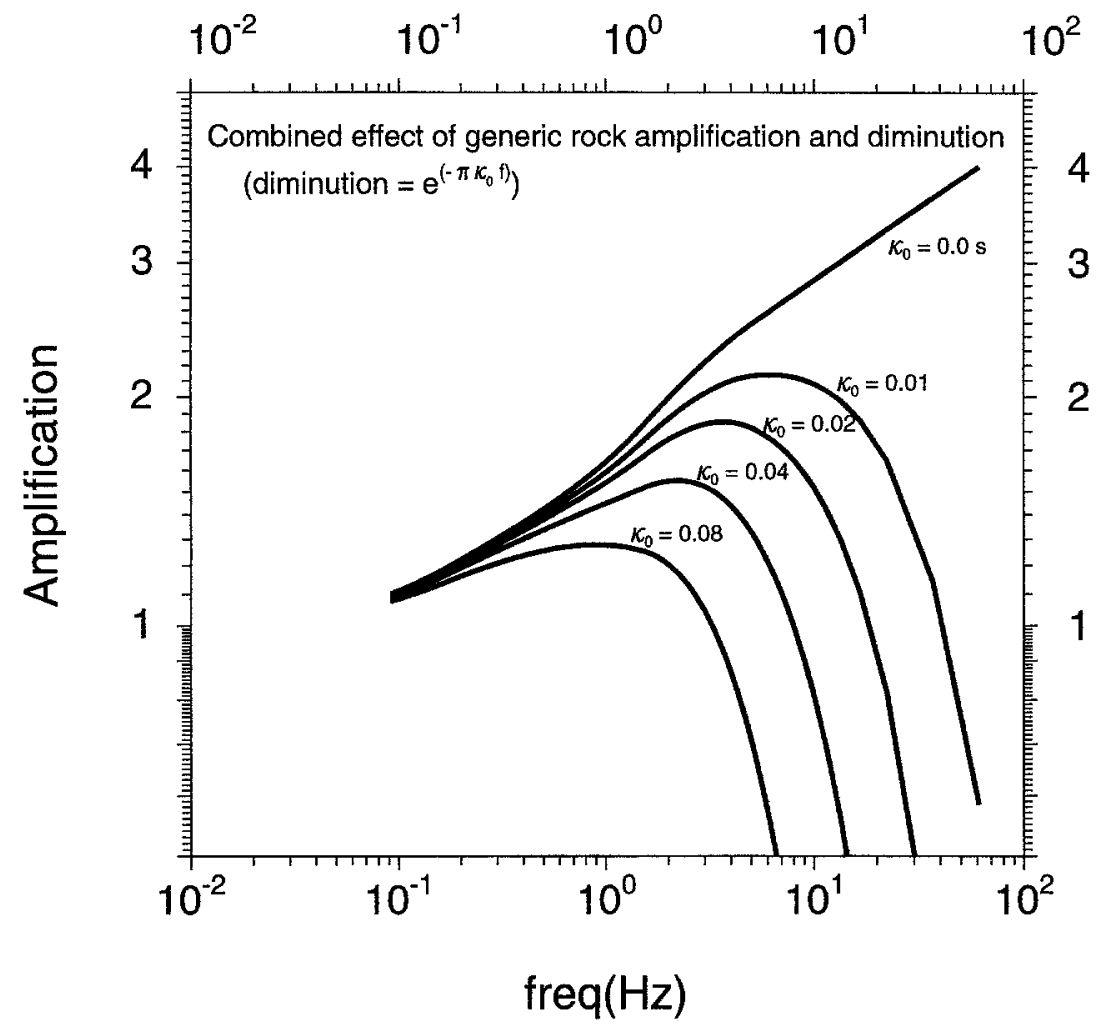

Figure 8. The combined effect of the generic rock amplification given in Table 3 and the attenuation given by $\exp \left(-\pi \kappa_{0} f\right)$.

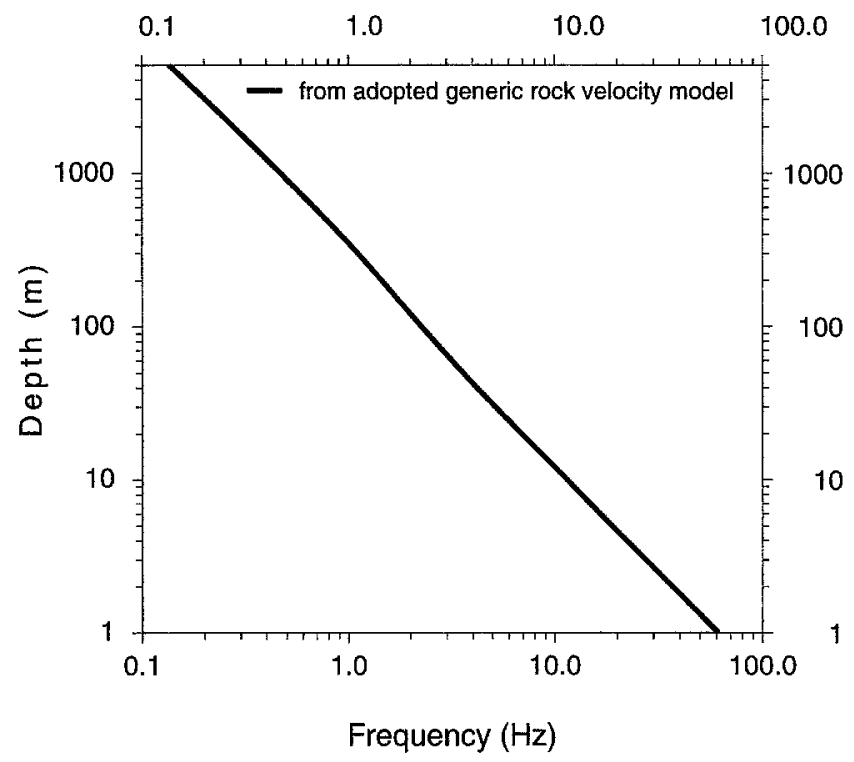

Figure 9. The depth corresponding to a quarter wavelength as a function of frequency for the adopted rock shear-wave velocity model. This figure provides a rough idea of what depths influence what frequencies in the site response.

The studies of Youngs and Silva (1992), Silva and Darragh (1995), and Atkinson and Silva (1997) used the amplifications of Boore (1986), which are essentially flat at high frequency, unlike the increasing amplification for the amplifications in this article. Anderson and Hough (1984) made no mention of amplification, but their measurement of $\kappa_{0}$ is independent of amplification as long as the amplification is constant over the frequency range used in measuring $\kappa$. As discussed later, the $\kappa_{0}$ measured with our amplification is about $0.006 \mathrm{sec}$ higher than it would be if we had assumed a constant amplification.

\section{0-m Time-Averaged Velocity for Rock and Soil Sites}

A site measure of importance in predicting ground shaking and in building codes (e.g., Boore et al., 1994; Borcherdt, 1994; Midorikawa et al., 1994) is the time-averaged shear-wave velocity from the surface to $30-\mathrm{m}$ depth $\left[\bar{V}_{30}=\right.$ $30 / S_{t t}(30 \mathrm{~m})$, where the units of $\bar{V}_{30}$ are $\left.\mathrm{m} / \mathrm{sec}\right]$. The traveltime curve fit to the data in Figure 3 yields an average velocity of $618 \mathrm{~m} / \mathrm{sec}$; a similar analysis for the soil subset of the borehole database yields $306 \mathrm{~m} / \mathrm{sec}$. Based on these results, we suggest that average rock and soil sites in western North America correspond to average velocities of 620 and $310 \mathrm{~m} / \mathrm{sec}$, respectively. These numbers can be used to compare ground-motion attenuation equations base on rock and soil site classifications with those that use $\bar{V}_{30}$ to characterize the geology at a site.

\section{Amplifications for Other Site Classes}

It is useful to obtain amplification functions for sites other than the very hard rock and rock sites. Rather than 

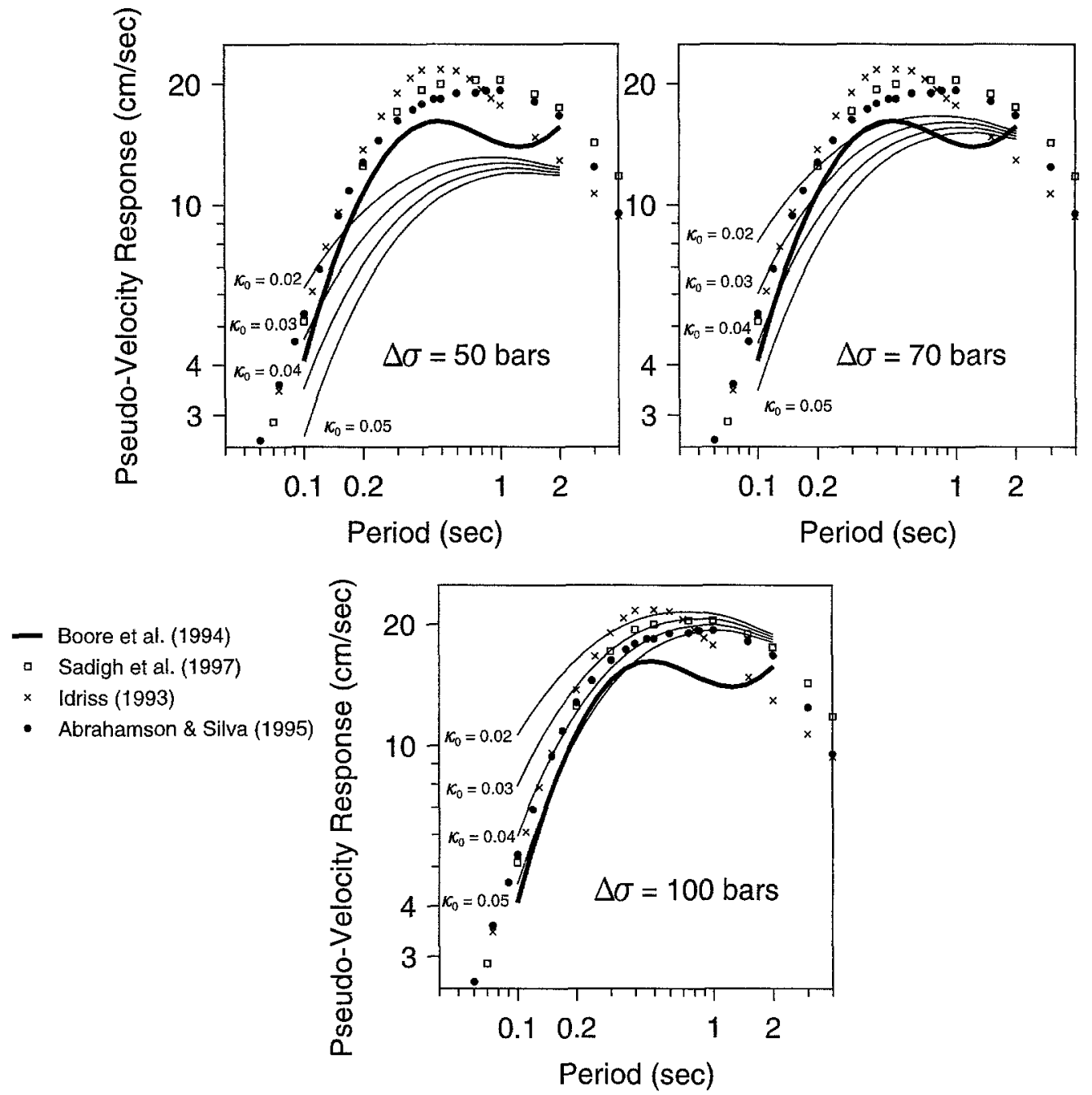

Figure 10. Response spectra at a horizontal distance of $20 \mathrm{~km}$ and a magnitude of 6.5 from empirical regression equations of Boore et al. (1993, 1994, 1997), Idriss (1993), Abrahamson and Silva (1995), and Sadigh et al. (1997) and stochastic-model simulations (light lines) that use the amplifications in Table 3 (the simulations were for a slant distance of $20.7 \mathrm{~km}$ to account for the parameter " $\mathrm{h}$ " in the empirical equations of Boore $e t a l$.). The parameters used in the simulations, other than $\Delta \sigma$ and $\kappa_{0}$, can be found in Appendix G of Boore (1996).

repeat the analysis of this article for boreholes falling into other classes, we use a combination of the rock amplification in Table 3 and the empirical results of Boore et al. (1994) in which response spectra are given as a function of $\bar{V}_{30}$. Our scheme is simple: We use the ratio of response spectra computed from Boore et al. (1994) for sites with $\bar{V}_{30}=620 \mathrm{~m} /$ sec and $\bar{V}_{30}$ equal to the desired velocity as a correction factor applied to the Table 3 amplifications. We used subjective judgment to extend the correction factors to frequencies outside the range used by Boore et al. (1994). The procedure assumes that the ratio of Fourier and response spectra are the same. This is not strictly true, particularly at frequencies higher than about $8 \mathrm{~Hz}$. We fine tune the amplifications by generating simulated response spectra for the desired $\bar{V}_{30}$ and comparing them with the empirical response spectra of Boore et al. (1994). Ratios of the spectra for various frequencies are used in an iterative procedure to adjust the amplifications. The final results are given in Table 5. We chose three site classes: the NEHRP building code classes $C$ and D (BSSC, 1994) and the average soil class. $\bar{V}_{30}$ for the two NEHRP classes ( 520 and $255 \mathrm{~m} / \mathrm{sec}$ ) are given by the geometrical means of the velocities defining the boundaries of each class. The velocity for an average soil site ( 310 $\mathrm{m} / \mathrm{sec}$ ) was discussed in the previous section.

We show the combined effect of amplification and attenuation in Figure 11. The site effect for the soil sites exceeds a factor of 2 over a wide range of frequencies of importance in engineering. The attenuation parameter $\kappa_{0}$ was held fixed at $0.035 \mathrm{sec}$ in the derivation of the amplifications, and therefore, any use of the amplifications in Table 5 should also use 
Table 5

Node Points of Amplification for Various Sites Characterized by the Average Shear-Wave Velocity over the Upper $30 \mathrm{~m}$

\begin{tabular}{cccc}
\hline & \multicolumn{3}{c}{ Amplification* } \\
\cline { 2 - 4 } Freq. (Hz) & $\begin{array}{c}\bar{V}_{30}=520 \mathrm{~m} / \mathrm{sec} \\
\text { (NEHRP class C) }\end{array}$ & $\begin{array}{c}\bar{V}_{30}=310 \mathrm{~m} / \mathrm{sec} \\
\text { (generic soil) }\end{array}$ & $\begin{array}{c}\bar{V}_{30}=255 \mathrm{~m} / \mathrm{sec} \\
\text { (NEHRP class D) }\end{array}$ \\
\hline 0.01 & 1.00 & 1.00 & 1.00 \\
0.09 & 1.21 & 1.34 & 1.43 \\
0.16 & 1.32 & 1.57 & 1.71 \\
0.51 & 1.59 & 2.24 & 2.51 \\
0.84 & 1.77 & 2.57 & 2.92 \\
1.25 & 1.96 & 2.76 & 3.10 \\
2.26 & 2.25 & 2.98 & 3.23 \\
3.17 & 2.42 & 2.95 & 3.18 \\
6.05 & 2.70 & 3.05 & 3.18 \\
16.60 & 3.25 & 3.18 & 3.18 \\
61.20 & 4.15 & 3.21 & 3.18 \\
\hline
\end{tabular}

*Values assume $\kappa_{0}=0.035 \mathrm{sec}$ and are based on the generic rock amplifications (Table 3), modified by the Boore et al. (1994) site factors for frequencies between 0.5 and $10 \mathrm{~Hz}$. The modifications for frequencies outside this range are based on subjective judgment and are not constrained by data. Amplifications at frequencies other than those tabulated are obtained by interpolation, assuming a linear dependence between log frequency and $\log$ amplification (c.g., function site_amp_factor in rvtdsubs. for of Boore, 1996).

$\kappa_{0}=0.035 \mathrm{sec}$ if the results are to be consistent with our study. Consistent results can also be obtained for other values of $\kappa_{0}$ as long as the amplification is adjusted by the factor $\exp \left[-\pi\left(\kappa_{0}-\kappa_{\text {new }}\right) f\right]$. The new amplification factor will not necessarily be adequately described by a straight line relating $\log$ amplification to $\log$ frequency using the frequency node points in the tables, and therefore, the amplifications in the tables should be evaluated at more closely spaced frequencies before being corrected for differences in $\kappa_{0}$.

\section{Conclusions and Discussion}

Using borehole data and studies of crustal velocities, we have estimated seismic shear-wave velocity and density as a function of depth for two classes of rock sites: rock sites such as are found in many tectonically active regions and very hard rock sites that are present in areas where glaciers have scoured the weathered and cracked near-surface materials. The very hard rock sites have average near-surface shear-wave velocities $\left(\bar{V}_{30}\right)$ in excess of $2 \mathrm{~km} / \mathrm{sec}$, while the rock sites have an average $\bar{V}_{30}$ of $620 \mathrm{~m} / \mathrm{sec}$. Very hard rock sites are of engineering importance in many parts of eastern North America, while rock occurs in much of western North America. A strictly geographic separation is tempting but not appropriate, however: In any region, rock sites might fall into either class or might fall between the two classes. From the shear-wave velocity and density versus depth functions, we produce amplifications as a function of frequency for use in simulations of strong ground motion. The amplifications on very hard rock sites are small (less than 1.2), but those on the rock sites can be in excess of 3.5 at high frequencies. Attenuation, however, will reduce these amplifications such that the combined effect for the rock sites might have a maximum of about a factor of 1.8 for $\kappa_{0}=$ $0.02 \mathrm{sec}$ and 1.5 for $\kappa_{0}=0.04 \mathrm{sec}$. The scatter in the amplifications computed for individual boreholes (Fig. 2) is considerable, suggesting that the mean amplifications proposed in this article should be used with caution for sitespecific studies. The large variation in site response for rock sites has also been emphasized by Schneider and Silva (1994).

In principle, rock sites can be found with a continuum of $\bar{V}_{30}$. We have separated rock sites into two generic classes-rock and very hard rock-on several bases: the geographic regions of particular importance in predictions of strong motion at rock sites and the availability of borehole data at rock sites. The very hard rock sites are characteristic of several highly urbanized areas in eastern North America, and the generic rock sites are commonly found in the urbanized tectonically active portions of western North America. Of course, the latter region includes coastal California, and this is the region that provides the bulk of the borehole shear-wave velocity measurements. We speculate that the distribution of $\bar{V}_{30}$ might in fact be bimodal, with the lowvelocity part of the distribution being given by Figure 1 and the presumed very high near-surface velocities in the Canadian Shield and other glaciated regions of North America forming another peak in the distribution at high velocities. We have almost no data, however, to support this speculation. If the speculation is true, it supports our choice of two rock classes; if not, we think the choice is justified by the agreement of our classes with the rocks most commonly encountered in practical applications. No matter how one chooses classes of rock sites, it is important to keep in mind that there is no single amplification function and attenuation parameter that can characterize all rock sites.

Although we have treated them separately, there may be a correlation between the attenuation parameter $\kappa_{0}$ and $\bar{V}_{30}$. This is certainly the case in going from very hard rock, for which $\kappa_{0}$ is often less than $0.01 \mathrm{sec}$ (e.g., Atkinson, 1996), to ordinary rock, for which we and others find representative values near $0.04 \mathrm{sec}$ for $\kappa_{0}$. There may also be a tendency within the generic rock category for $\kappa_{0}$ to decrease with increasing $\bar{V}_{30}$ (W. Silva, written comm., 1995). Correlations between $\kappa_{0}$ and $\bar{V}_{30}$, however, might depend on geographic region and class of geologic materials beneath a site. $\kappa_{0}$ is affected by more of the travel path than the part contributing to the amplification (Anderson et al., 1996). For this reason, two sites with the same $\bar{V}_{30}$ could have different values of $\kappa_{0}$ [as has been found by Atkinson (1996) for very hard-rock sites in southeastern and southwestern Canada, with $\kappa_{0}$ being less than 0.004 for sites in the former region and 0.011 for sites in the latter region]. In addition, the correlation between $\kappa_{0}$ and $\bar{V}_{30}$ is probably different for rock and for soils. We expect that near-surface velocity gradients in soils would be less than in rocks and that scattering would be less important in soils. For these reasons, the amplifica- 


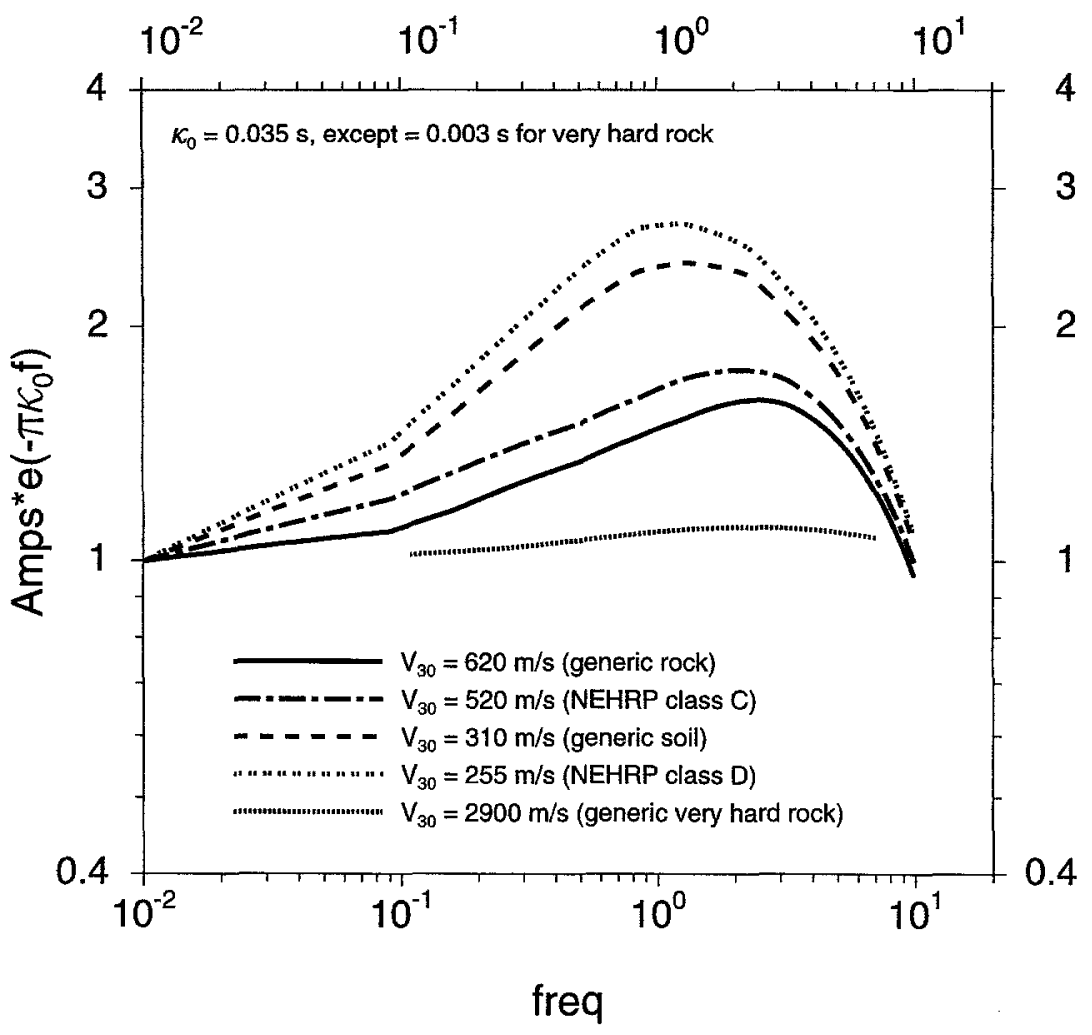

Figure 11. The product of Fourier spectral amplifications and the diminution factor $\exp \left(-\pi \kappa_{0} f\right)$ for various site conditions, as measured by the average shear-wave velocity in the upper $30 \mathrm{~m}$. The amplifications were obtained using the tabulated values in Tables 3 , 4 , and $5 ; \kappa=0.035 \mathrm{sec}$ for all but the very hard-rock site, for which $\kappa=0.003 \mathrm{sec}$. tion function and $\kappa_{0}$ might be different for two sites with the same $\bar{V}_{30}$.

Although our primary reason for separating the effects of amplification and attenuation is for convenience in providing input parameters for our computer codes for estimating ground shaking, we note that measurements of $\kappa_{0}$ from data also use a similar separation. Any measurement of $\kappa_{0}$ is tied to the amplification. In most cases of measurements of $\kappa_{0}$, however, the amplification is implicitly assumed to be unity, or at least independent of frequency over the range used in determining $\kappa_{0}$, a result that the borehole data suggests is unlikely to be true. The high-frequency dependence of the amplification, however, is critically dependent on the gradient of the velocity with depth near the surface (e.g., less than $10 \mathrm{~m}$ for $f>10 \mathrm{~Hz}$, according to Fig. 9). In order for the rock amplifications to flatten for frequencies greater than $10 \mathrm{~Hz}$, the gradient in the upper $10 \mathrm{~m}$ would have to be replaced by a constant velocity layer. The borehole data in Figure 3 argues against this, at least for rock sites. If $\kappa_{0}$ is independent of frequency, then in principle it should be possible to distinguish between a site with constant amplification at high frequency and one with increasing amplification: A plot of the $\log$ of the spectrum versus linear frequency will approach a straight line in the former case, while an increasing amplification will lead to curvature of the highfrequency part of the spectrum. To study this, we replotted Figure 8 using log, linear axes. The curvature was very hard to see and would be completely obscured for real, noisy data.
On the other hand, determinations of $\kappa_{0}$ by fitting a straight line to $\log$ spectrum versus frequency (Anderson and Hough, 1984) yields estimates near 0.034 for the case when $\kappa_{0}$ is 0.040 . Therefore, as expected, measurements of $\kappa_{0}$ that do not account for increasing amplification with frequency will be lower than measurements that account for the amplification. Caution must be used in comparing values of $\kappa_{0}$ from various studies; it is necessary to consider what, if any, account has been taken of amplification of the spectrum.

As the example above illustrates, derived parameters are dependent on the assumptions embedded in the underlying model, a point that we fear is often overlooked. Another example is in the estimation of seismic moments of small earthquakes at rock sites, which are usually determined with no regard for the amplifications that can occur due to the decrease in seismic velocities near the Earth's surface; Figure 8 suggests that such determinations might be systematically high by a factor of about 1.4 for many rock sites (those with $\bar{V}_{30}$ considerably less than several $\mathrm{km} / \mathrm{sec}$ ) if computed from waves with frequencies of $1 \mathrm{~Hz}$. The factor would be more than 1.4 for soil sites.

We made a preliminary application of the new amplifications to estimate values of $\Delta \sigma=70$ bars and $\kappa_{0}=0.035$ sec for rock sites in western North America by attempting to match our empirically determined response spectra at a distance of $20 \mathrm{~km}$ for an $\mathbf{M} 6.5$ earthquake.

We also find from the analysis of borehole data that average rock and soil sites are characterized by time-aver- 
aged shear-wave velocities in the upper $30 \mathrm{~m}$ of 620 and $310 \mathrm{~m} / \mathrm{sec}$, respectively.

The rock amplifications have been modified to obtain amplification factors that are appropriate for sites classified by average shear-wave velocities $\vec{V}_{30}$ equal to 520,310 , and $255 \mathrm{~m} / \mathrm{sec}$. These site classes correspond to NEHRP class $\mathrm{C}$, average soil, and NEHRP class D, respectively. The combined effect of the amplification and attenuation reaches a factor of 2.7 for $\bar{V}_{30}=255 \mathrm{~m} / \mathrm{sec}$ and exceeds a factor of 2 for a wide range of frequencies of engineering interest.

We stress the obvious point that rock sites on which strong motions have been recorded are not underlain by uniform half-spaces; our analysis of borehole data finds a strong gradient with depth, presumably due to weathering processes and open fractures. It would be a mistake, however, to assume that the same gradients apply to the rock beneath soil sites. If rock recordings are to be used as input to a soil column, then these rock recordings should first be deconvolved to a depth where the velocity profile is comparable to the rock beneath the soil column (that depth could be 1 $\mathrm{km}$ or more), before being convolved with the response of the rock between that depth and the base of the soil column. This is a site-specific matter and requires the determination of shear velocity to sufficient depths, both beneath the rock recording and beneath the soil column.

\section{Acknowledgments}

We thank Jim Gibbs for helping enter the borehole data and Charles Mueller for use of his program Rattle. Jim Gibbs and Tom Fumal provided unpublished travel-time data for two boreholes, and Joe Fletcher supplied computer files of $S_{t t}$ for several rock sites in southern California (Keenwild and Pinyon Flat). Harold Magistrale provided velocity and density profiles for a few locations, also in southern California. We also thank Rachel $\mathrm{Ab}-$ ercrombie, Peter Malin, and Tom McEvilly for data and information about the Cajon Pass, Parkfield area, and Oroville boreholes. We are grateful to Walt Silva for his discussions and comments. In addition, Norm Abrahamson, Gail Atkinson, Sue Hough, Charles Mueller, John Schneider, and Robert Youngs provided thoughtful reviews of the manuscript. This work was partially supported by the U.S. Nuclear Regulatory Commission.

\section{References}

Abercrombie, R. E. (1997). Near surface attenuation and site effects from comparison of surface and deep borehole recordings, Bull. Seism. Soc. Am. 87 (in press).

Abrahamson, N. A. and W. Silva (1995). A consistent set of ground motion attenuation relations including data from the 1994 Northridge earthquake (abstract), Seism. Res. Lett. 66, 23.

Anderson, J. G. and S. E. Hough (1984). A model for the shape of the Fourier amplitude spectrum of acceleration at high frequencies, Bull. Seism. Soc. Am. 74, 1969-1993.

Anderson, J. G., Y. Lee, Y. Zeng, and S. Day (1996). Control of strong motion by the upper 30 meters, Bull. Seism. Soc. Am. 86, 1749-1759.

Atkinson, G. M. (1996). The high-frequency shape of the source spectrum for earthquakes in eastern and western Canada, Bull. Seism. Soc. Am. 86, 106-112.

Atkinson, G. M. and D. M. Boore (1995). Ground motion relations for eastern North America, Bull. Seism. Soc. Am. 85, 17-30.

Atkinson, G. M. and W. Silva (1997). An empirical study of earthquake source spectra for California earthquakes, Bull. Seism. Soc. Am. 87, 97-113.

Blakeslee, S. and P. Malin (1991). High-frequency site effects at two Parkfield downhole and surface stations, Bull. Seism. Soc. Am. 81, 332345.

Boore, D. M. (1986). Short-period $P$ - and $S$-wave radiation from large earthquakes: implications for spectral scaling relations, Bull. Seism. Soc. Am. 76, 43-64.

Boore, D. M. (1996). SMSIM-Fortran programs for simulating ground motions from earthquakes: version 1.0, U.S. Geol. Surv. Open-File Rept. 96-80-A, 96-80-B, 69 pp.

Boore, D. M. and G. M. Atkinson (1987). Stochastic prediction of ground motion and spectral response parameters at hard-rock sites in eastern North America, Bull. Seism. Soc. Am. 77, 440-467.

Boore, D. M. and W. B. Joyner (1991). Estimation of ground motion at deep-soil sites in eastern North America, Bull. Seism. Soc. Am. 81, $2167-2185$.

Boore, D. M., W. B. Joyner, and L. Wennerberg (1992). Fitting the stochastic $\omega^{-2}$ source model to observed response spectra in western North America: trade-offs between $\Delta \sigma$ and $\kappa$, Bull. Seism. Soc. Am. 82, 1956-1963.

Boore, D. M., W. B. Joyner, and T. E. Fumal (1993). Estimation of response spectra and peak accelerations from western North American earthquakes: an interim report, U.S. Geol. Surv. Open-File Rept. 93-509, $72 \mathrm{pp}$.

Boore, D. M., W. B. Joyner, and T. E. Fumal (1994). Estimation of response spectra and peak accelerations from western North American earthquakes: an interim report, Part 2, U.S. Geol. Surv. Open-File Rept. 94-127, $40 \mathrm{pp}$.

Boore, D. M., W. B. Joyner, and T. E. Fumal (1997). Equations for estimating horizontal response spectra and peak acceleration from western North American earthquakes: a summary of recent work, Seism. Res. Lett. (in press).

Borcherdt, R. D. (1994). Estimates of site-dependent response spectra for design (methodology and justification), Earthquake Spectra 10, 617653.

Building Seismic Safety Council (BSSC) (1994). NEHRP recommended provisions for seismic regulations for new buildings, Part 1-Provisions, FEMA 222A, Federal Emergency Management Agency, 290 pp.

Christensen, N. I. (1996). Poisson's ratio and crustal seismology, J, Geophys. Res. 101, 3139-3156.

Christensen, N. I. and W. D. Mooney (1995). Seismic velocity structure and composition of the continental crust: a global view, J. Geophys. Res. 100, 9761-9788.

Clark, S. P., Jr. (Editor) (1966). Handbook of Physical Constants, Geol. Soc. Am. Mem. 97,587 pp.

Daley, T. M. and T. V. McEvilly (1990). Shear-wave anisotropy in the Parkfield Varian well VSP, Bull. Seism. Soc. Am. 80, 857-869.

Day, S. M. (1996). RMS response of a one-dimensional halfspace to $\mathrm{SH}$, Bull. Seism. Soc. Am. 86, 363-370.

Electric Research Power Institute (EPRI) (1993). Guidelines for Determining Design Basis Ground Motions, Report No. TR-102293, Vols. $1-5$.

Fletcher, J. B., T. Fumal, H.-P. Liu, and L. C. Carroll (1990). Near-surface velocities and attenuation at two boreholes near Anza, California, from logging data, Bull. Seism. Soc. Am. 80, 807-831.

Fumal, T. E. (1978). Correlations between seismic wave velocities and physical properties of near-surface geologic materials in the southern San Francisco Bay region, California, U.S. Geol. Surv. Open-File Rept. 78-1067, 114 pp.

Fumal, T. E., J. F. Gibbs, and E. F. Roth (1981). In-situ measurements of seismic velocity at 19 locations in the Los Angeles, California region, U.S. Geol. Surv. Open-File Rept. 81-399, 121 pp.

Fumal, T. E., J. F. Gibbs, and E. F. Roth (1982a). In-situ measurements of seismic velocity at 10 strong motion accelerograph stations in central California, U.S. Geol. Surv. Open-File Rept. 82-407, 76 pp. 
Fumal, T. E., J. F. Gibbs, and E. F. Roth (1982b). In-situ measurements of seismic velocity at 22 locations in the Los Angeles, California region, U.S. Geol. Surv. Open-File Rept. 82-833, 138 pp.

Fumal, T. E., J. F. Gibbs, and E. F. Roth (1984). In-situ measurements of seismic velocity at 16 locations in the Los Angeles, California, region, U.S. Geol. Surv. Open-File Rept. 84-681, 109 pp.

Gibbs, J. F. (1989). Near-surface $P$ - and $S$-wave velocities from borehole measurements near Lake Hemet, California, U.S. Geol. Surv. OpenFile Rept. 89-630.

Gibbs, J. F. and T. E. Fumal (1994). Seismic velocities and geologic logs from borehole measurements at seven strong-motion stations that recorded the 1989 Loma Prieta, California, earthquake, Part IV, U.S. Geol. Surv. Open-File Rept. 94-552, 89 pp.

Gibbs, J. F., T. E. Fumal, and R. D. Borcherdt (1975). In-situ measurements of seismic velocities at twelve locations in the San Francisco Bay region, U.S. Geol. Surv. Open-File Rept. 75-564, 87 pp.

Gibbs, J. F., T. E. Fumal, and R. D. Borcherdt (1976). In-situ measurements of seismic velocities in the San Francisco Bay region . . Part II, U.S. Geol. Surv. Open-File Rept. 76-731, 145 pp.

Gibbs, J. F., T. E. Fumal, and R. D. Borcherdt (1977). In-situ measurements of seismic velocities in the San Francisco Bay region . . Part III, U.S. Geol. Surv. Open-File Rept. 77-850, 143 pp.

Gibbs, J. F., T. E. Fumal, and E. F. Roth (1980). In-situ measurements of seismic velocity at 27 locations in the Los Angeles, California, region, U.S. Geol. Surv. Open-File Rept. 80-378, 167 pp.

Gibbs, J. F., E. F. Roth, T. E. Fumal, N. A. Jasek, and M. A. Emslie (1990). Seismic velocities from borehole measurements at four locations along a fifty-kilometer section of the San Andreas fault near Parkfield, California, U.S. Geol. Surv. Open-File Rept. 90-248, 35 pp.

Gibbs, J. F., T. E. Fumal, D. M. Boore, and W. B. Joyner (1992). Seismic velocities and geologic logs from borehole measurements at seven strong-motion stations that recorded the Loma Prieta earthquake, U.S. Geol. Surv. Open-File Rept. 92-287, $139 \mathrm{pp}$

Gibbs, J. F., T. E. Fumal, and T. J. Powers (1993). Seismic velocities and geologic logs from borehole measurements at eight strong-motion stations that recorded the 1989 Loma Prieta, California, earthquake, U.S. Geol. Surv. Open-File Rept. 93-376, 119 pp.

Gibbs, J. F., T. E. Fumal, and T. J. Powers (1994a). Seismic velocities and geologic logs from borehole measurements at seven strong-motion stations that recorded the 1989 Loma Prieta, California, earthquake, U.S. Geol. Surv. Open-File Rept. 94-222, 104 pp.

Gibbs, J. F., T. E. Fumal, R. D. Borcherdt, R. E. Warrick, H.-P. Liu, and R. E. Westerlund (1994b). Seismic velocities and geologic logs from boreholes at three downhole arrays in San Francisco, California, U.S. Geol. Surv. Open-File Rept. 94-706, 40 pp.

Hadley, D. and H. Kanamori (1977). Seismic structure of the Transverse Ranges, California, Geol. Soc. Am. Bull. 88, 1469-1478.

Haskell, N. A. (1960). Crustal reflection of plane $S H$ waves, J. Geophys. Res. 65, 4147-4150.

Hauksson, E. (1987). Seismotectonics of the Newport-Inglewood fault zone in the Los Angeles basin, southern California, Bull. Seism. Soc. Am. 77, 539-561.

Hauksson, E. and L. M. Jones (1988). The July 1986 Oceanside $\left(M_{L}=\right.$ 5.3) earthquake sequence in the continental borderland, southern California, Bull. Seism. Soc. Am. 78, 1885-1906.

Hazlewood, R. M. (1974). Preliminary report of seismic refraction survey along the east side of the San Francisco Bay, Alameda County, California, U.S. Geol. Surv. Open-File Rept., 10 pp.

Hazlewood, R. M. and W. B. Joyner (1973). Preliminary report of seismic refraction survey, Redwood Shores, San Mateo County, California, U.S. Geol. Surv. Open-File Rept., 9 pp.

Hough, S. E., J. G. Anderson, J. Brune, F. Vernon III, J. Berger, J. Fletcher,
L. Haar, T. Hanks, and L. Baker (1988). Attenuation near Anza, California, Bull. Seism. Soc. Am. 78, 672-691.

Idriss, I. M. (1993). Procedures for Selecting Earthquake Ground Motions at Rock Sites-A Report to the National Institute of Standards and Technology, Department of Civil and Environmental Engineering , University of California, Davis, revised 1993.

Joyner, W. B. and D. M. Boore (1981). Peak horizontal acceleration and velocity from strong-motion records including records from the 1979 Imperial Valley, California, earthquake, Bull. Seism. Soc. Am. 71, 2011-2038.

Joyner, W. B. and D. M. Boore (1982). Prediction of earthquake response spectra, U.S. Geol. Surv. Open-File Rept. 82-977, 16 pp.

Joyner, W. B., R. E. Warrick, and T. E. Fumal (1981). The effect of Quaternary alluvium on strong ground motion in the Coyote Lake, California, earthquake of 1979, Bull. Seism. Soc. Am. 71, 1333-1349.

Magistrale, H., K. McLaughlin, and S. Day (1996). A geology-based 3D velocity model of the Los Angeles basin sediments, Bull. Seism. Soc. Am. 86, 1161-1166.

Malin, P. E., J. A. Waller, R. D. Borcherdt, E. Cranswick, E. G. Jensen, and J. Van Schaack (1988). Vertical seismic profiling of Oroville microearthquakes: velocity spectra and particle motion as a function of depth, Bull. Seism. Soc. Am. 78, 401-420.

Midorikawa, S., M. Matsuoka, and K. Sakugawa (1994). Site effects on strong-motion records observed during the 1987 Chiba-Ken-TohoOki, Japan, earthquake, Proc. of the 9th Japan Earthquake Engineering Symposium, Vol. 3, E085-E090.

Nicholson, C. and D. W. Simpson (1985). Changes in $V_{p} / V_{s}$ with depth: implications for appropriate velocity models, improved earthquake locations, and material properties of the upper crust, Bull. Seism. Soc. Am. 75, 1105-1123.

Sadigh, K., C.-Y. Chang, J. A. Egan, F. Makdisi, and R. R. Youngs (1997). Attenuation relationships for shallow crustal earthquakes based on California strong motion data, Seism. Res. Lett. (in press).

Schneider, J. F. and W. J. Silva (1994). What is rock? Implications for site response estimation (abstract), Seism. Res. Lett. 65, 44.

Silva, W. J. and R. B. Darragh (1995). Engineering Characterization of Strong Ground Motion Recorded at Rock Sites, Electric Power Research Institute, Palo Alto, California, Report No. TR-102262.

Steidl, J. H., A. G. Tumarkin, and R. J. Archuleta (1996). What is a reference site?, Bull. Seism. Soc. Am. 86, 1733-1748.

Thiel Jr., C. C. and J. F. Schneider (1993). Investigations of thirty-three Loma Prieta earthquake strong motion recording sites, final report of project sponsored by the Building Contractors Society of Japan and the Electric Power Research Institute, California Universities for Research in Earthquake Engineering (CUREe), Dept. of Civil Engineering, Stanford Univ., Stanford, California.

Wald, D. J., D. V. Helmberger, and T. H. Heaton (1991). Rupture model of the 1989 Loma Prieta earthquake from the inversion of strongmotion and broadband teleseismic data, Bull. Seism. Soc. Am. 81, $1540-1572$.

Youngs, R. R. and W. J. Silva (1992). Fitting the $\omega^{-2}$ Brune source model to California empirical strong motion data (abstract), Seism. Res. Lett. 63,34 .

U.S. Geological Survey

Mail Stop 977

345 Middlefield Road

Menlo Park, California 94025

E-mail: boore@samoa.wr.usgs.gov;joyner@samoa.wr.usgs.gov

Manuscript received 16 May 1996. 